\title{
Crisis Information Seeking and Sharing (CISS): Scale Development for Measuring Publics' Communicative Behavior in Social-Mediated Public Health Crises
}

\author{
Yen-I Lee (D) and Yan Jin \\ Grady College of Journalism and Mass Communication, University of Georgia, \\ Athens, Georgia, USA
}

\begin{abstract}
This study first refines the conceptual framework of publics' communicative behavior in socialmediated health crises. Then two multiple-item scales for measuring publics' health crisis information seeking and sharing (CISS) are developed and tested by employing online survey data sets from a random national sample of 279 adults and 280 adults in the United States, respectively. Results indicate seven types of crisis information seeking behavior and 17 types of crisis information sharing behavior crossing over platforms, channels, and information sources. The CISS scales provide a valid and reliable tool for crisis communication researchers and practitioners to measure publics' information seeking and sharing activities in social-mediated public health crisis communication.
\end{abstract}

KEYWORDS: Crisis communication; health crisis; scale development; social media; information seeking and sharing

Public health crises, such as infectious disease outbreaks, whether ongoing (e.g., HIV/AIDS), recurring (e.g., seasonal influenza), or sporadic (e.g., SARS), can imperil the health of large numbers of individuals and severely threaten the social and economic well-being of affected publics and their communities (Morens \& Fauci, 2013). The urgent need for effective public health crisis communication was highlighted in 2014, when the largest Ebola outbreak in history ravaged West Africa, and again in 2015-2016, as the Zika virus first arrived in the Western Hemisphere and spread rapidly throughout South America and in the United States. In addition to the infectious nature of such diseases,

CONTACT Yen-I Lee•E-mail: yeni.lee25@uga.edu•Grady College of Journalism and Mass Communication, University of Georgia, 120 Hooper St., Athens, GA 30602, USA

๑ 2019 by Journal of International Crisis and Risk Communication Research. All rights reserved. 
fear-based conversations about them have the potential quickly to go viral and spread around the world (Dredze, Broniatowski, \& Hilyard, 2016). Publics' communication needs in public health crises are more critical than ever (Thelwall \& Stuart, 2007).

Crisis communication scholars have laid the theoretical foundation for understanding publics' immense and immediate communication needs, namely, information seeking, which addresses the need for information, and information sharing, which addresses the need for spreading information (Thelwall \& Stuart, 2007). Crisis information and publics' communicative behavior regarding crisis information play a fundamental role in crisis escalation and can impact publics' understanding and interpretation of a crisis situation (Schultz \& Raupp, 2010; Van der Meer, 2016). In the context of public health crises, Seeger (2006) pointed out that government health agencies' efforts have been directed toward merging an organization-reputation-focused crisis communication approach with risk communication that largely focuses on gaining publics' attention to health risks (Witte, 1995), gradually resulting in a more comprehensive approach called "crisis and emergency risk communication (CERC)" (Reynolds, Galdo, \& Sokler, 2002). In discussing the Centers for Disease Control and Prevention's (CDC) Zika communication needs, Reynolds (2016) highlighted the importance of understanding what information people seek and how they seek information from health agencies to empower people/citizens to take control in health crisis situations.

Furthermore, crisis information seeking and crisis information sharing are identified by the social-mediated crisis communication (SMCC) model as two distinct constructs and as core behavioral outcomes of crisis communication online and offline (Jin \& Liu, 2010; Liu, Austin, \& Jin, 2011; Liu, Fraustino, \& Jin, 2015, 2016; Liu, Jin, Briones, \& Kuch, 2012). Despite the pivotal role communication plays in public health crises, significant knowledge gaps remain regarding the most effective strategies for communicating uncertainty and risk during emergencies like infectious disease outbreaks (Liu, Bartz, \& Duke, 2016). These findings indicate the importance of further examining how and what types of online and offline communication channels publics seek and on which they share health crisis information to reduce uncertainty and risk during health crises. 
In terms of the measurement of crisis information communicative behavior, previous SMCC research, primarily focused on organizational crises and terrorist attacks, has assessed publics' communicative behavior at the manifest variable level, using sets of individual action items representing information seeking and sharing (Austin, Liu, \& Jin, 2012; Jin, Liu, \& Austin, 2014; Liu et al., 2016; Liu, Jin, \& Austin, 2013). Only a recent study identified clusters of publics' information seeking behavior (i.e., information seeking on social media vs. on television) and information sharing behavior (i.e., information sharing on social media vs. through interpersonal channels) at the latent construct level (Jin, Fraustino, \& Liu, 2016). However, the structures and qualities of those crisis information seeking and sharing (CISS) clusters need to be further assessed and improved, as Jin and colleagues (2016) acknowledged.

To respond to the need to identify more stable structures of information seeking and information sharing actions, this study develops and tests two multiple-item scales for measuring publics' CISS in socialmediated public health crises based on two survey data sets from a random sample of adults in the United States. The CISS scales provide a valid and reliable tool for public relations researchers and crisis communication managers to measure publics' communicative behavior in social-mediated public health crises.

\section{Conceptualization of CISS in Social- Mediated Public Health Crises}

\section{Crisis Information Seeking Behavior}

Information seeking, as an attentive and active type of public communication behavior (Moon, Rhee, \& Yang, 2016), refers to "planned scanning of the environment for messages about a specified topic" (Clarke \& Kline, 1974, p. 233). Some researchers have operationalized health crisis information seeking at the cognitive and affective levels, focusing on perceived channel importance for seeking health crisis information (Avery, 2010) and interest in obtaining health crisis information (Spence, Lachlan, Edwards, \& Edwards, 2016). Other researchers have approached health crisis information at the behavioral level, examining information seeking as the frequency of use of different channels 
(Wang \& Ahern, 2015) and the likelihood of channel use for information seeking (Kuttschreuter et al., 2014).

Health information seeking is defined as the action of searching and receiving messages that help "to reduce uncertainty regarding health status" and "construct a social and personal (cognitive) sense of health" (Tardy \& Hale, 1998, p. 338). Existing literature on publics' health information seeking has emphasized health information seeking through traditional mass media, health professionals, and interpersonal communication (Avery, 2010; Wang \& Ahern, 2015). Recently, social media channels, such as Twitter, Facebook, blogs, and online videos, have been studied in terms of where publics seek health-related information for topics including the effects of information content of routine and crisis situations, vaccination during the $\mathrm{H}_{1} \mathrm{~N}_{1}$ flu epidemic, and food-related risk (Kuttschreuter et al., 2014; Spence et al., 2016). These studies have indicated the need to fully examine how and where publics seek information across a variety of social media platforms and communication channels, in particular when a sporadic and urgent health crisis situation occurs.

In a field experiment using a representative national sample, Liu and colleagues (2016) reported that after initial exposure to a disaster situation, crisis information sources seem to affect individuals' intended crisis information seeking actions from television, local government websites, and federal government websites. Jin and colleagues (2016) further identified two clusters for publics' crisis information seeking behavior across different information sources, namely, local media, national media, local government, and federal government. The first cluster, crisis information seeking on social media, included online video, Facebook page updates, Twitter, others' blogs, and picture sharing sites. The second cluster focused on crisis information seeking on television. These studies have shown the importance of social media and mass media information sources for publics seeking crisis information. However, the question remains, how and where do publics seek health crisis information across traditional media, social media, and interpersonal information sources? 


\section{Crisis Information Sharing Behavior}

Researchers have examined the role of social media in information sharing. Lariscy, Avery, Sweetser, and Howes (2009) defined social media as "online practices that utilize technology and enable people to share content, opinions, experiences, insights, and media themselves" (p. 314). Despite the lack of consensus across disciplines on how to define social media, public relations scholars have endorsed that "social media combine an eclectic range of online word-of-mouth forums including blogs, discussion boards and chat rooms; consumer-to-consumer e-mail; consumer product or service ratings websites and forums; Internet discussion boards and forums; moblogs; and social networking websites" (Mangold \& Faulds, 2009, p. 358; see also Palenchar \& Freberg, 2012). During a crisis, publics can be engaged with organizations via their "views, likes, comments, and shares" in response to crisis information disseminated by organizations and other sources on social media platforms (Smith \& Gallicano, 2015, p. 82).

In times of public health crisis, health agencies often disseminate health crisis information and preventive action recommendations through various communication channels to reach different target publics that can help further share the health crisis information with other individuals and groups (Vijaykumar, Jin, \& Nowak, 2015). Existing empirical studies, however, have only provided evidence for crisis information sharing on a single platform of social media, such as Twitter (Freberg, Saling, Vidoloff, \& Eosco, 2013; Shklovski, Burke, Kiesler, \& Kraut, 2010; Sutton, 2010). As a result, findings cannot be applied to crisis information sharing across different social media platforms. In addition, despite the fact that research has repeatedly revealed that both information form and source can influence publics' CISS behaviors (Austin et al., 2012; Lachlan, Spence, \& Seeger, 2009; Liu et al., 2013, 2015, 2016; Schultz, Utz, \& Göritz, 2011; Utz, Schultz, \& Glocka, 2013), the current literature in public health crisis lacks measurement specification in terms of where and how health crisis information sharing actions take place across various communication channels and different platforms.

Liu and colleagues (2016) conducted a field experiment on disaster 
communication using a representative national sample. The key findings revealed that regardless of crisis information form and source, individuals reported the strongest intentions to share information about the disaster predominately via offline interpersonal channels rather than through online organizational and personal channels. Jin and colleagues (2016) further identified two clusters for publics' crisis information sharing behavior. First was crisis information sharing on social media, including posting on Facebook; re-tweeting at least one tweet, such as a government Facebook post about the crisis; sharing a government Facebook post about the crisis on their own Facebook page; commenting on a government Facebook page about the crisis; posting information on their friends' Facebook pages or groups about the crisis; tweeting about the crisis; writing a blog post on their own blog about the crisis; posting a comment on someone else's blog about the crisis; making a comment on someone else's online video about the crisis; and uploading a picture related to the crisis on a dedicated photo sharing site. Second was information sharing through interpersonal chan$n e l s$, including telling people they know via face-to-face conversations about the crisis, telling people they know by e-mailing them about the crisis, calling people they know by phone to talk about the crisis, and texting people they know about the crisis. These findings indicate the need for crisis communication researchers to further examine how and where publics share health crisis information across different social media platforms, such as Instagram, Pinterest, Twitter, and Facebook, because of the different features of each social media platform.

\section{CISS Theoretical Framework}

The implications of pioneering studies in crisis communication are twofold. First, information seeking and sharing are two constructs composed of multiple actions taken by publics that need to be assessed at the behavioral level (Jin et al., 2016; Liu et al., 2016). Second, to comprehensively capture publics' CISS actions, researchers should not only include channels and platforms of crisis information but also consider the ownership or source of different online channels and platforms (Jin et al., 2016; Liu et al., 2016). However, existing studies have only used hypothetical terrorist attack cases to examine publics' information 
seeking and sharing behaviors and only examined two social media platforms (i.e., Facebook and Twitter). These findings do not provide a full picture of how publics use different communication channels from different sources to seek and share health crisis information.

To fill this research gap, this study proposed a refined theoretical framework for CISS in public health crises. The CISS framework posits that crisis information seeking and sharing actions should be examined at the behavioral level as core communicative behavior outcomes of public health crisis communication. It takes publics' varied communication activities into account to capture a fuller spectrum of their CISS actions: (a) communication via online public channels (e.g., different social media platforms and websites) and interpersonal channels (e.g., texting and phone calls) and (b) communication activities engaging different crisis information sources (e.g., traditional news media, health organizations, and peers).

Therefore, based on this proposed CISS framework, as a first step of scale development for measuring publics' communicative behavior in social-mediated public health crises, this study focused on how to measure publics' information seeking and sharing actions taken via online platforms and offline channels and across traditional news media, health organization sources, and peer sources.

\section{Method and CISS Scale Development}

\section{Initial CISS Items and Procedures}

Based on existing literature of crisis information seeking and information sharing in SMCC (Austin et al., 2012; Jin et al., 2016; Liu et al., 2013; Liu, Fraustino et al., 2016), a 12-item scale of social-mediated crisis information seeking and a 21-item scale of social-mediated crisis information sharing (CISS) in public health crisis were generated (see Appendixes A and B).

Data were collected using Qualtrics survey panels in the context of an infectious disease outbreak (i.e., the spread of Zika virus as a health threat to U.S. residents) in April 2016, for a total of 279 U.S. adults in Sample 1 and 280 U.S. adults in Sample 2. Survey participants were randomly assigned to read 1 of 12 crisis information messages. 
Messages included the same text, "Zika is an infectious disease spread by mosquitos," but a varied message frame (loss vs. gain), image type (photo vs. infographic), and information source (traditional media vs. health organization vs. peer). Given the context of public health crises, the Centers for Disease Control and Prevention (CDC) was used as the representative government health agency directly involved with Zika crisis communication to publics. The condition variables assessed for a separate study were not included, as this study was solely interested in identifying the clusters and patterns of publics' communicative behavior. In other words, this study focused only on how and where publics sought and shared health crisis information across different social media platforms and communication channels.

After reading about the Zika crisis, participants were asked to respond to survey questions regarding their level of agreement or disagreement with each of the listed information seeking and sharing actions. Participants' assessments of their agreement with items regarding their information seeking and information sharing behaviors were measured on a 7-point Likert-type scale ranging from 1 (strongly disagree) to 7 (strongly agree). For each item, participants were provided "N/A" as an answer choice option if they thought that any question was not applicable to them. Appendixes A and B present the instructions and all survey items measuring health CISS, respectively.

Data gathered for crisis information seeking behavior and crisis information sharing behavior were further analyzed using scale development procedures as reported in the following sections.

\section{Crisis Information Seeking Behavior}

Item reduction. Survey Sample $1(N=279)$ was used for item reduction and exploratory factor analysis. As an initial reduction method, item distributions were examined aiming at eliminating highly skewed and unbalanced distributions due to insufficient information, limited variability, and highly unstable correlational results (Clark \& Watson, 1995). The results of frequency tables and kurtosis indicated a normal distribution for all 12 items included in the scale.

Second, following the item-screening processes recommended by Matsunaga (2010) and the rule of thumb that factor correlation matrix values should be greater than .30 in large data sets (Field, 2013; 
Meyers, Gamst, \& Guarino, 2013), a principal component analysis (PCA) with promax rotation was used to generate a theoretical solution uncontaminated by unique and error variability. In addition, the analysis only emphasized the variance that each observed variable shared with other observed variables (Tabachnick \& Fidell, 2001). All items had higher scores that represented stronger agreement with information seeking action on a 7-point Likert scale. Prior to data analysis, the Kaiser-Meyer-Olkin (KMO) test of sampling adequacy and the Bartlett test of sphericity were used to determine the appropriateness of factor analysis (Kaiser \& Rice, 1974). The KMO level of .90 and the significance of the Bartlett test (.oo) indicated that factor analysis was appropriate for the data (Kaiser \& Rice, 1974). In this initial step, all components that had eigenvalues greater than 1 were extracted. The analysis returned two components with initial eigenvalues greater than 1 (explaining $65.25 \%$ of the variance).

Exploratory factor analysis. After the initial analysis for item reduction, because correlation between factors was expected theoretically, and communality better estimates the shared variance in a measurement (Costello \& Osborne, 2005; Jin, Liu, Anagondahalli, \& Austin, 2014; Meyers et al., 2013), an exploratory factor analysis (EFA) was performed using principal axis factoring with promax rotation on the 12 items of information seeking action. Items having factor loadings of less than .40 or cross-loading of the two components were considered poor and were eliminated (Tabachnick \& Fidell, 2001). In addition, any items with a communality value less than .50 were dropped from the final solution (Meyers et al., 2013). As a result, five items (looking for more information from traditional news media, online videos, Facebook page updates, others' blogs, and primary health care provider) were deleted. Follow-up factor analyses on the remaining items suggested a 7 -item scale with two underlying factors representing clusters of information seeking action for the Zika virus health crisis from social media platforms and interpersonal channels. Factor 1 is information seeking via social media platforms, including Twitter, Instagram, Pinterest, and Snapchat. Factor 2 is information seeking through interpersonal channels, including face-to-face and/or phone conversation, e-mailing people one knows, and texting people one knows.

The resulting subscales demonstrated internal consistency, $\alpha=.93$ 
$(M=3.38, S D=2.01$; four items for information seeking via social media platforms $)$ and $\alpha=.84(M=4.10, S D=1.70$; three items for information seeking through interpersonal channels). The results matched Clark and Watson's (1995) recommendations for a coefficient alpha benchmark of .80 . The results indicate that the 7 -item instrument measuring information seeking behavior for the public health crisis through various social media platforms and interpersonal channels satisfied internal consistency within each factor and that the subscales for each cluster of platforms and channels were reasonable and parsimonious.

Confirmatory factor analysis. Survey Sample $2(N=280)$ was used for confirmatory factor analysis. To identify the factor structure by conducting confirmatory factor analysis (CFA), AMOS 23 was used for these factors with a 7 -item oblique model to evaluate the adequacy of the hypothesized factor structure. Maximum likelihood estimation was employed. A variety of goodness-of-fit indices indicated that the estimated model fit the observed data, $\chi^{2}(12, N=280)=27.43, p \leq .01$, with root mean square error of approximation (RMSEA) $=.07$, which was higher than the acceptable good fit cutoff of .o6 ( Hu \& Bentler, 1999); comparative fit index (CFI) = .99; and goodness-of-fit index $(\mathrm{GFI})=.97$. The data indicated a reasonable fit to the hypothesized two-factor oblique model. Results of EFA and CFA factor loadings for the 7-item crisis information seeking scale are shown in Table 1.

\section{Crisis Information Sharing Behavior}

Item reduction. Survey Sample $1(N=279)$ was used for item reduction and EFA. As an initial reduction method, item distributions were examined aiming at eliminating highly skewed and unbalanced distributions due to insufficient information, limited variability, and highly unstable correlational results (Clark \& Watson, 1995). The results of frequency tables and kurtosis showed a normal distribution for all 21 items included in the scale.

Second, following the item-screening processes recommended by Matsunaga (2010) and the rule of thumb that factor correlation matrix values should be greater than .30 in large data sets (Field, 2013; Meyers et al., 2013), a PCA with promax rotation was used to generate a theoretical solution uncontaminated by unique and error variability. In addition, 
TABLE 1 Structural Analysis of Crisis Information Seeking Scale

\begin{tabular}{lll}
\hline \multicolumn{1}{c}{ Item } & Factor loading EFA & CFA \\
\hline Factor 1: Social media platforms ${ }^{\mathbf{a}}$ & & \\
Twitter & 0.77 & 0.84 \\
Instagram & 0.95 & 0.97 \\
Pinterest & 0.89 & 0.89 \\
Snapchat & 0.90 & 0.91 \\
Factor 2: Interpersonal channels ${ }^{\mathbf{b}}$ & & \\
Face-to-face and/or phone conversation & 0.62 & 0.59 \\
E-mailing people one knows & 0.90 & 0.84 \\
Texting people one knows & 0.87 & 0.95 \\
\hline
\end{tabular}

Note. All CFA loadings significant at $p \leq .001$. CFA $=$ confirmatory factor analysis. EFA = exploratory factor analysis.

${ }^{\mathrm{a}} \mathrm{a}=.93 ; M=3.38 ; S D=2.01 .{ }^{\mathrm{b}} \mathrm{a}=.84 ; M=4.10 ; S D=1.70$.

the analysis only emphasized the variance that each observed variable shared with other observed variables (Tabachnick \& Fidell, 2001). All items had higher scores that represented stronger agreement with information sharing action on a 7-point Likert scale. Prior to data analysis, the study used the KMO test of sampling adequacy and the Bartlett test of sphericity to determine the appropriateness of factor analysis (Kaiser \& Rice, 1974). The KMO level of .94 and the significance of the Bartlett test (.oo) indicated that the factor analysis was appropriate for the data (Kaiser \& Rice, 1974). Moreover, in this initial step, all components that had eigenvalues greater than 1 were extracted. The analysis returned three components with initial eigenvalues greater than 1 (explaining $75.54 \%$ of the variance).

Exploratory factor analysis. After the initial analysis for item reduction for information sharing action, because correlations between factors were expected theoretically, and communality better estimates shared variance in a measurement (Costello \& Osborne, 2005; Jin, Liu, Anagondahalli, \& Austin, 2014; Meyers et al., 2013), an EFA was performed using principal axis factoring with promax rotation on the 21 items of information sharing action. Items having factor loadings of 
less than .40 or cross-loading of the two components were considered poor and were eliminated (Tabachnick \& Fidell, 2001). In addition, any items with a communality value less than .50 were dropped from the final solution (Meyers et al., 2013). As a result, four items (tell people one knows via face-to-face and/or phone conversations, post information about Zika on my friends' Facebook profiles or groups, post comments in others' blogs, and post comments in others' online videos about Zika) were deleted. Follow-up factor analyses on the remaining items suggested a 17-item scale with three underlying factors representing clusters of information sharing action for the Zika virus health crisis from social media platforms and interpersonal channels: Factor 1 is information sharing via non-Facebook social media platforms, including re-tweeting a CDC tweet, tweeting about Zika, writing blog posts, uploading pictures to Instagram, uploading pictures to Pinterest, liking CDC Instagram posts, sharing CDC Instagram posts on one's own Instagram profile, commenting on the CDC's Instagram page, liking CDC Pinterest posts, repinning a CDC Pinterest post on one's own Pinterest profile, and commenting on the CDC's Pinterest profile. Factor 2 is information sharing through interpersonal channels, including: e-mail people one knows, call people one knows, and text people one knows. Factor 3 is information sharing via CDC Facebook, including liking CDC Facebook posts, sharing CDC posts on one's own Facebook page, and commenting on the CDC Facebook page.

The resulting subscales demonstrated internal consistency, $\alpha=.97$ $(M=3.67, S D=1.98 ; 11$ items for information sharing via non-Facebook social media platforms), $\alpha=.86(M=4.11, S D=1.76$; 3 items for information sharing through interpersonal channels), and $\alpha=.89(M=4.68$, $S D=1.75 ; 3$ items for information sharing via CDC Facebook). The results matched Clark and Watson's (1995) recommendations for a coefficient alpha benchmark of .80. The results indicate that the 17 -item instrument measuring information sharing behavior for the public health crisis through various platforms and communication channels satisfied internal consistency within each factor and that the subscales for each cluster of media platforms were reasonable and parsimonious.

Confirmatory factor analysis. Survey Sample $2(N=280)$ was used for CFA. To identify the factor structure by conducting CFA, AMOS 
TABLE 2 Structural Analysis of Crisis Information Sharing Scale

\begin{tabular}{|c|c|c|}
\hline Items & Factor loadings EFA & CFA \\
\hline \multicolumn{3}{|l|}{$\begin{array}{l}\text { Factor } 1 \text { : Non-Facebook social media } \\
\text { platforms }{ }^{\mathrm{a}}\end{array}$} \\
\hline Re-tweet a CDC tweet & 0.77 & 0.77 \\
\hline Tweet about Zika & 0.82 & 0.79 \\
\hline Write blog posts & 0.73 & 0.75 \\
\hline Upload pictures to Instagram & 0.88 & 0.81 \\
\hline Upload pictures to Pinterest & 0.87 & 0.81 \\
\hline Like CDC Instagram post & 0.83 & 0.83 \\
\hline $\begin{array}{l}\text { Share CDC Instagram post on one's } \\
\text { own Instagram profile }\end{array}$ & 0.87 & 0.86 \\
\hline Comment on CDC Instagram page & 0.93 & 0.86 \\
\hline Like CDC Pinterest post & 0.90 & 0.90 \\
\hline $\begin{array}{l}\text { Repin a CDC Pinterest post on one's } \\
\text { own Pinterest profile }\end{array}$ & 0.90 & 0.91 \\
\hline Comment on CDC Pinterest profile & 0.90 & 0.91 \\
\hline \multicolumn{3}{|l|}{ Factor 2: Interpersonal channels ${ }^{b}$} \\
\hline E-mail people one knows & 0.81 & 0.62 \\
\hline Call people one knows & 0.76 & 0.69 \\
\hline Text people one knows & 0.87 & 0.69 \\
\hline \multicolumn{3}{|l|}{ Factor 3: CDC Facebook ${ }^{c}$} \\
\hline Like CDC Facebook post & 0.87 & 0.81 \\
\hline Share CDC post on my Facebook page & 0.89 & 0.79 \\
\hline Comment on CDC Facebook page & 0.77 & 0.81 \\
\hline
\end{tabular}

Note. All CFA loadings significant at $p \leq .001$. CFA $=$ confirmatory factor analysis. EFA = exploratory factor analysis.

${ }^{\mathrm{a}} \mathrm{a}=.97 ; M=3.67 ; S D=1.98 .{ }^{\mathrm{b}} \mathrm{a}=.86 ; M=4.11 ; S D=1.76 .{ }^{\mathrm{c}} \mathrm{a}=.89 ; M=4.68 ; S D=1.75$. 
23 was used for these factors with a 17-item oblique model to evaluate the adequacy of the hypothesized factor structure. Maximum likelihood estimation was employed. A variety of goodness-of-fit indices indicated if an estimated model fit the observed data, $\chi^{2}(106, N=280)=$ 282.01, $p \leq .001$ (RMSEA $=.08, \mathrm{CFI}=.96$, and GFI $=.89)$ lower than the acceptable good fit cutoff of .9o. The data indicated a reasonable fit to the hypothesized three-factor oblique model. Results of EFA and CFA factor loadings for the 17-item crisis information sharing scale are shown in Table 2.

\section{Discussion}

\section{The CISS Scales}

Under the overarching umbrella of "communicative behavior" in SMCC (Liu et al., 2015; Liu, Fraustino et al. 2016), publics' information seeking and sharing actions are two distinct types of behavior. This refined operationalization demands valid and reliable scales be developed to measure the two core behavior outcome variables identified by SMCC (Jin \& Liu, 2010; Liu et al., 2011, 2012). This study, focusing on public health crisis situations, developed and tested the CISS scales.

Crisis information seeking scale. The crisis information seeking scale of the CISS includes two clusters/subscales: (a) a 4-item subscale for information seeking via social media platforms-Twitter, Instagram, Pinterest, and Snapchat-and (b) a 3-item subscale for information seeking through interpersonal channels, including face-to-face and/or phone conversation, e-mailing people one knows, and texting people one knows.

Crisis information sharing scale. The crisis information sharing scale of the CISS includes three clusters/subscales: (a) an 11-item subscale for information sharing via non-Facebook social media platforms, including re-tweeting a CDC tweet, tweeting about Zika, writing blog posts, uploading pictures to Instagram, uploading pictures to Pinterest, liking CDC Instagram posts, sharing CDC Instagram posts on one's own Instagram profile; commenting on the CDC Instagram page, liking a CDC Pinterest post, repinning a CDC Pinterest post on one's own Pinterest profile, and commenting on the CDC Pinterest profile; 
(b) a 3-item subscale for information sharing through interpersonal channels, including e-mailing people I know, calling people I know, and texting people I know; and (c) a 3-item subscale for information sharing via CDC Facebook, including liking a CDC Facebook post, sharing a CDC post on one's own Facebook page, and commenting on the CDC Facebook page. It is particularly interesting to see that the CDC Facebook page is rendered as one critical space where people go for health crisis information sharing. In public health crisis situations, health organizations' official Facebook pages seem to present a unique communication opportunity. As a federal health agency in the United States, the CDC has established its Facebook page as an influential health information authority on social media that directly disseminates crisis information to its Facebook group followers, who then spread such information to their friends and followers via liking, sharing, and commenting functions.

The CISS scales reported here are a tool that can be utilized by crisis researchers and managers in capturing the multiple facets of publics' communicative behavior during a public health crisis. The CISS scales can be useful for health organizations to capture publics' crisis information seeking and sharing actions via various channels and media platforms. They can also help health organizations evaluate publics' crisis information engagement level. The CISS scales thus contribute to crisis communication measurement by adding comprehensive clusters of health crisis-triggered communicative behavior.

\section{Implications for Crisis Communication}

\section{Research and Practice}

The CISS scales and our empirical findings echo previous crisis studies that social media channels are important for crisis information seeking (Kuttschreuter et al., 2014; Spence et al., 2016) and further provide a comprehensive understanding of how publics perceive the function of each social media platform for CISS in public health crises. In examining the CISS scales and subscales, a few notable patterns provide implications for both crisis researcher and practitioners.

First, despite its popularity, Facebook is not the go-to social media platform for publics to seek public health crisis information. Publics 
tend to go to other social media platforms, such as Twitter, Instagram, Pinterest, and Snapchat, to find out more about what is going on and what to do about a health crisis. Although the survey participants in our study reported the CDC Facebook page as one of the most important places for them to share crisis information about Zika via liking a CDC post, sharing a CDC post, and commenting on the CDC Facebook page, it is unclear whether this is associated with the organization itself (i.e., CDC) or typical Facebook engagement behavior due to platform popularity. Nevertheless, this seems to indicate a unique opportunity, to be further explored and examined, for government agencies to utilize Facebook as an information sharing forum where publics, especially influential social media followers, can help spread timely and accurate information to their connected friends on social media (Jin \& Liu, 2010; Liu et al., 2012).

Second, when it comes to CISS, other social media platforms (e.g., Twitter, Instagram, and Pinterest) function as tools to seek and share health crisis information for publics. Government health agencies, compared to corporations and nonprofit organizations, tend to adapt new social media platforms at a slower rate. Our findings suggest that government health agencies need to consider expanding their social media toolboxes, visual social media platforms in particular (e.g., Instagram and Pinterest), and tailoring social media strategies and tactics, which will contribute to more effective crisis preparedness, response, and recovery.

Third, interpersonal channels, such as texting and e-mailing, are important for both seeking and sharing public health crisis information, which corresponds to previous findings that individuals have a high tendency to share crisis information predominately via interpersonal channels rather than through online organizational and personal channels (Liu, Fraustino et al., 2016). The findings further provide evidence that texting and e-mailing are the two preferred information seeking and sharing communicative behaviors when publics use interpersonal communication to learn and spread information about a health crisis.

Fourth, the factor analyses yielded two surprising findings. The first was the weak loadings on a few items related to offline interpersonal channels (i.e., face-to-face conversation, phone call, text, and emails) in 
CISS scales. Publics seem to prefer texting others, talking with someone face-to-face, calling someone on the phone, or e-mailing someone to learn about or share health crisis information. Our findings suggest a need and opportunity for health organizations to tailor health crisis information dissemination according to publics' offline interpersonal communication channel preferences. Although mobile technology allows one to call, e-mail, and text others, its texting function needs to be tapped more in times of health crisis. Health organizations need to have mobile-friendly crisis information ready to be sought out and shared further by mobile phone users. The second surprise was that none of the three factors for crisis information sharing includes Facebook in general, although there are some activities not tied to the CDC's social platforms (i.e., Factor 3 is specific to the CDC Facebook page). The mixture of information sharing activities tied to sharing CDC-sourced information and those regarding general (nonsourced) posts/comments, as rendered and confirmed statistically, is intriguing. It suggests that when it comes to where and how publics share health crisis information, the boundary between sourced and nonsourced is more blurred than expected, which merits further investigation.

\section{Limitations and Future Directions}

As the first study developing multiple-item scales for measuring publics' communicative behavior in SMCC, this study examined the conceptualization and operationalization of publics' crisis information seeking and their crisis information sharing. Findings reveal distinctive clusters representing different information seeking and sharing actions by publics. However, the focus on public health crises may limit the generalizability of the conclusions and the CISS scales' applicability to a broader range of crisis situations, such as organizational crises and other types of public emergency crises.

First, the external validity of the study is limited because Zika was still in early stages when the survey data collection took place. Thus participants were asked to speculate on further Zika information sharing. In addition, there might be social desirability issues, as the participants may view any information coming from the CDC as legitimate in general and regard the $\mathrm{CDC}$ as a primary source of information during a 
health crisis. Therefore the results may not reflect the full picture of reality when participants choose information sources during health crises.

Second, the predictability of the CISS scales is yet to be tested, which will provide further information on whether the two types of crisis information seeking behavior and three types of crisis information sharing behavior will contribute to effectively predicting publics' communicative responses to crisis type, information source and information form, and so on.

Third, this study did not measure attitude toward the source of the crisis information, which might impact publics' health CISS activities. Future studies should further examine how individuals' attitudes toward information might influence their health crisis communicative behavior across social media platforms.

In sum, this study is a significant step toward developing a valid and reliable measure of publics' communicative responses in SMCC evoked by a severe public health threat. How health organizations and news media understand, facilitate, and effectively respond to publics' CISS actions will provide important insights for health organizations to build community resilience, gain publics' support, and capitalize on the opportunity to engage influential social media followers on social media platforms to jointly spread timely and accurate health crisis information to individuals and communities in need. 


\section{Appendix A: Crisis Information Seeking Survey Instructions and Items}

Instruction: Please indicate how much you agree with each of the following information seeking actions, after reading the post about Zika, by clicking the number that best indicates the extent of your agreement/ disagreement. If the question is not applicable to you, select "N/A."

The 12 initial information seeking behavior items include the following: (a) "I would look for more information from traditional news media (e.g., newspaper, TV news, etc.)"; (b) "I would look for more information from online videos (e.g., YouTube videos)"; (c) "I would look for more information from Facebook page updates"; (d) "I would look for more information from Twitter"; (e) "I would look for more information from others' blogs"; (f) "I would look for more information on Instagram"; (g) "I would look for more information on Pinterest"; (h) "I would look for more information from Snapchat"; (i) I "would look for more information by talking to people I know via face-to-face and/or phone conversations"; (j) "I would look for more information by e-mailing people I know"; (k) "I would look for more information by texting people I know"; and (l) "I would look for more information from my primary health care provider."

\section{Appendix B: Crisis Information Seeking Survey Instructions and Items}

Instruction: Please indicate how much you agree/disagree with each of the following actions, after reading the post about Zika, by clicking the number that best indicates the extent of your agreement. If the question is not applicable to you, select "N/A."

The 21 initial information sharing behavior items include the following: (a) "I would tell people I know (e.g., family, friends and coworkers, etc.) via face-to-face and/or phone conversations about [health crisis]"; (b) "I would tell people I know (e.g., family, friends and coworkers, etc.) by e-mailing them about [health crisis]"; (c) "I would call people I know (e.g., family, friends and co-workers, etc.) to talk about [health crisis]"; (d) "I would text people I know (e.g., family, friends and 
co-workers, etc.) about [health crisis]"; (e) "I would 'like' a CDC [Centers for Disease Control and Prevention] Facebook post about [health crisis]"; (f) "I would 'share' a CDC Facebook post about [health crisis] on my Facebook page"; (g) "I would comment about [health crisis] on CDC Facebook page"; (h) "I would post information about [health crisis] on my friends' Facebook profiles or groups"; (i) "I would re-tweet a CDC tweet"; (j) "I would tweet about [health crisis]"; (k) "I would write blog posts about [health crisis] on my own blog"; (l) "I would post comments about [health crisis] on others' blogs"; (m) "I would make comments in the comment section of others' online videos about [health crisis]'; (n) "I would upload pictures related to [health crisis] to Instagram"; (o) "I would upload pictures related to [health crisis] to Pinterest"; (p) "I would 'like' a CDC Instagram post about [health crisis]"; (q) "I would 'share' a CDC Instagram post about [health crisis] on my Instagram profile"; (r) "I would comment about [health crisis] on CDC's Instagram page"; (s) "I would 'like' a CDC Pinterest post about [health crisis]"; ( $t$ ) "I would repin a CDC Pinterest post about [health crisis] on my Pinterest profile"; and (u) "I would comment about [health crisis] on CDC's Pinterest profile." 


\section{Acknowledgment}

The authors thank the Department of Advertising and Public Relations in the Grady College of Journalism and Mass Communication at the University of Georgia for the funding support for this research project.

Yen-I Lee is a $\mathrm{PhD}$ candidate in the Grady College of Journalism and Mass Communication at the University of Georgia. Her research focuses on strategic communication and health communication. Specifically, her research examines how health message campaigns and human-technology interaction use shape publics' discrete emotional, cognitive, and behavioral changes in the context of health risks and crisis communication.

Yan Jin, $\mathrm{PhD}$, is a professor and assistant department head of advertising and public relations, as well as associate director of the Center for Health and Risk Communication, at the Grady College of Journalism and Mass Communication, University of Georgia. Her primary research programs are in the areas of crisis communication and strategic health risk communication, focusing on the role of emotions and social media in crisis communication theory and application.

\section{ORCID}

Yen-I Lee (1) https://orcid.org/oooo-0oo1-7820-6568 


\section{References}

Austin, L., Liu, B. F., \& Jin, Y. (2012). How audiences seek out crisis information: Exploring the social-mediated crisis communication model. Journal of Applied Communication Research, 40, 188-207. https://doi.org/10.1080 /oo909882.2012.654498

Avery, E. (2010). Contextual and audience moderators of channel selection and message reception of public health information in routine and crisis situations. Journal of Public Relations Research, 22, 378-403. https://doi .org/10.1080/10627261003801404

Clark, L. A., \& Watson, D. (1995). Constructing validity: Basic issues in objective scale development. Psychological Assessment, 7, 309-319. https://doi .org/10.1037//1040-3590.7.3.309

Clarke, P., \& Kline, F. G. (1974). Media effects reconsidered: Some new strategies for communication research. Communication Research, 1, 224-240. https://doi.org/10.1177/009365027400100205

Costello, A. B., \& Osborne, J. W. (2005). Best practices in exploratory factor analysis: Four recommendations for getting the most from your analysis. Practical Assessment, Research \& Evaluation, 10, 1-9.

Dredze, M., Broniatowski, D. A., \& Hilyard, K. M. (2016). Zika vaccine misconceptions: A social media analysis. Vaccine, 34, 3441-3442. https://doi .org/10.1016/j.vaccine.2016.05.008

Field, A. (2013). Discovering statistics using IBM SPSS statistics (4th ed.). Los Angeles, CA: Sage.

Freberg, K., Saling, K., Vidoloff, K. G., \& Eosco, G. (2013). Using value modeling to evaluate social media messages: The case of hurricane Irene. Public Relations Review, 39, 185-192. https://doi.org/10.1016/j.pubrev.2013.02.010

Hu, L. T., \& Bentler, P. M. (1999). Cutoff criteria for fit indexes in covariance structure analysis: Conventional criteria versus new alternatives. Structural Equation Modeling, 6, 1-55. https://doi.org/10.1080/1070551990954 0118

Jin, Y., Fraustino, J. D., \& Liu, B. F. (2016). The scared, the outraged, and the anxious: How crisis emotions, involvement, and demographics predict publics' conative coping. International Journal of Strategic Communication, 10, 289-308. https://doi.org/10.1080/1553118x.2016.1160401

Jin, Y., Liu, B. F., \& Austin, L. (2014). Examining the role of social media in 
effective crisis management: The effects of crisis origin, information form, and source on publics' crisis responses. Communication Research, 41, 74-94. https://doi.org/10.1177/0093650211423918

Jin, Y., Liu, B. F., Anagondahalli, D., \& Austin, L. (2014). Scale development for measuring publics' emotions in organizational crises. Public Relations Review, 40, 509-518. https://doi.org/10.1016/j.pubrev.2014.04.007

Jin, Y., \& Liu, B. F. (2010). The blog-mediated crisis communication model: Recommendations for responding to influential external blogs. Journal of Public Relations Research, 22, 429-455. https://doi.org/10.1080/10627261 003801420

Kaiser, H. F., \& Rice, J. (1974). Litter jiffy, Mark IV. Educational and Psychology Measurement, 34, 111-117. https://doi.org/10.1177/o01316447403400115

Kuttschreuter, M., Rutsaert, P., Hilverda, F., Regan, Á., Barnett, J., \& Verbeke, W. (2014). Seeking information about food-related risks: The contribution of social media. Food Quality and Preference, 37, 10-18. https://doi .org/10.1016/j.foodqual.2014.04.006

Lachlan, K. A., Spence, P. R., \& Seeger, M. (2009). Terrorist attacks and uncertainty reduction: Media use after September 11th. Behavioral Sciences of Terrorism and Political Aggression, 1, 101-110. https://doi.org/10.1080 /19434470902771683

Lariscy, R. W., Avery, E. J., Sweetser, K. D., \& Howes, P. (2009). An examination of the role of online social media in journalists' source mix. Public Relations Review, 35, 314-316. https://doi.org/10.1016/j.pubrev.2009.05 .008

Liu, B. F., Austin, L., \& Jin, Y. (2011). How publics respond to crisis communication strategies: The interplay of information form and source. Public Relations Review, 37, 345-353. https://doi.org/10.1016/j.pubrev.2011.08.004

Liu, B. F., Bartz, L., \& Duke, N. (2016). Communicating crisis uncertainty: A review of the knowledge gaps. Public Relations Review, 42, 479-487. https:// doi.org/10.1016/j.pubrev.2016.03.003

Liu, B. F., Fraustino, J. D., \& Jin, Y. (2015). How disaster information form, source, type, and prior disaster exposure affect public outcomes: Jumping on the social media bandwagon? Journal of Applied Communication Research, 43, 44-65. https://doi.org/10.1080/00909882.2014.982685

Liu, B. F., Fraustino, J. D., \& Jin, Y. (2016). Social media use during disasters: How information form and source influence intended behavioral 
responses. Communication Research, 43, 626-646. https://doi.org/10.1177 /0093650214565917

Liu, B. F., Jin, Y., \& Austin, L. A. (2013). The tendency to tell: Understanding publics' communicative responses to crisis information form and source. Journal of Public Relations Research, 25, 51-67. https://doi.org/10.1080/1062726x .2013 .739101

Liu, B. F., Jin, Y., Briones, R., \& Kuch, B. (2012). Managing turbulence online: Evaluating the blog-mediated crisis communication model with the American Red Cross. Journal of Public Relations Research, 24, 353-370. https://doi.org/10.1080/1062726X.2012.689901

Mangold, W. G., \& Faulds, D. J. (2009). Social media: The new hybrid element of the promotion mix. Business Horizons, 52, 357-365. https://doi .org/10.1016/j.bushor.2009.03.002

Matsunaga, M. (2010). How to factor-analyze your data right: Do's, don't's, and how-to's. International Journal of Psychological Research, 3, 97-110. https://doi.org/10.2150o/20112084.854

Meyers, L. S., Gamst, G., \& Guarino, A. J. (2013). Applied multivariate research (2nd ed.). Los Angeles, CA: Sage.

Moon, B. B., Rhee, Y., \& Yang, S. U. (2016). Developing public's information transmitting behavior (ITB) model in public relations: A cross-national study. Journal of Public Relations Research, 28, 4-18. https://doi.org/10.1080 /1062726x.2015.1107482

Morens, D. M., \& Fauci, A. S. (2013). Emerging infectious diseases: Threats to human health and global stability. PLoS Pathogens, 9(7), e1003467. https:// doi.org/10.1371/journal.ppat.1003467

Palenchar, M. J., \& Freberg, K. (2012). Emergency management planning: Risk, crises, issues, and social media. In B. A. Olanrian, D. E. Williams, \& W. T. Coombs (Eds.), Pre-crisis planning, communication, and management (pp. 147-169). New York, NY: Peter Lang.

Reynolds, B. (2016). Zika crisis and emergency risk communication (CERC) discussion: Survey of topics: What the public needs when risks are uncertain. Retrieved from https://stacks.cdc.gov/view/cdc/40820

Reynolds, B., Galdo, J., \& Sokler, L. (2002). Crisis and emergency risk communication. Atlanta, GA: Centers for Disease Control and Prevention. Schultz, F., \& Raupp, J. (2010). The social construction of crises in governmental and corporate communications: An inter-organizational and inter-systemic 
analysis. Public Relations Review, 36, 112-119. https://doi.org/10.1016/j .pubrev.2009.11.002

Schultz, F., Utz, S., \& Göritz, A. (2011). Is the medium the message? Perceptions of and reactions to crisis communication via Twitter, blogs and traditional media. Public Relations Review, 37, 20-27. https://doi.org/10.1016/j .pubrev.2010.12.001

Seeger, M. W. (2006). Best practices in crisis communication: An expert panel process. Journal of Applied Communication, 34, 232-244. https:// doi.org/10.1080/00909880600769944

Shklovski, I., Burke, M., Kiesler, S., \& Kraut, R. (2010). Technology adoption and use in the aftermath of Hurricane Katrina in New Orleans. American Behavioral Scientist, 53, 1228-1246. https://doi.org/10.1177/0002764209 356252

Smith, B. G., \& Gallicano, T. D. (2015). Terms of engagement: Analyzing public engagement with organizations through social media. Computers in Human Behavior, 53, 82-90. https://doi.org/10.1016/j.chb.2015.05.060 Spence, P. R., Lachlan, K. A., Edwards, A., \& Edwards, C. (2016). Tweeting fast matters, but only if I think about it: Information updates on social media. Communication Quarterly, 64, 55-71. https://doi.org/10.1080/01463373 .2015 .1100644

Sutton, J. N. (2010). Twittering Tennessee: Distributed networks and collaboration following a technological disaster. In S. French, B. Tomaszewski, \& C. Zobel (Eds.), ISCRAM 2010 Conference Proceedings: The 7 th International Conference on Information Systems for Crisis Response and Management (pp. 1-10). Seattle, WA: ISCRAM.

Tabachnick, B. G., \& Fidell, L. S. (2001). Using multivariate statistics (4th ed.). Needham Heights, MA: Allyn and Bacon.

Tardy, R. W., \& Hale, C. L. (1998). Getting "plugged in": A network analysis of health-information seeking among "stay-at-home moms." Communication Monographs, 65, 336-357. https://doi.org/10.1080/0363775980937 6457

Thelwall, M., \& Stuart, D. (2007). RUOK? Blogging communication technologies during crises. Journal of Computer-Mediated Communication, 12, 523-548. https://doi.org/10.1111/j.1083-6101.2007.00336.x

Utz, S., Schultz, F., \& Glocka, S. (2013). Crisis communication online: How medium, crisis type and emotions affected public reactions in the 
Fukushima Daiichi nuclear disaster. Public Relations Review, 39, 40-46. https://doi.org/10.1016/j.pubrev.2012.09.010

Van der Meer, T. G. L. A. (2016). Automated content analysis and crisis communication research. Public Relations Review, 42, 952-961. https://doi .org/10.1016/j.pubrev.2016.09.001

Vijaykumar, S., Jin, Y., \& Nowak, G. (2015). Social media and the virality of risk: The risk amplification through media spread (RAMS) model. Journal of Homeland Security and Emergency Management, 12, 653-677. https:// doi.org/10.1515/jhsem-2014-0072

Wang, W., \& Ahern, L. (2015). Acting on surprise: Emotional response, multiple-channel information seeking and vaccination in the $\mathrm{H}_{1} \mathrm{~N}_{1}$ flu epidemic. Social Influence, 10, 137-148. https://doi.org/10.1080/15534510.2015.1011227

Witte, K. (1995). Generating effective risk messages: How scary should your risk communication be? Communication Yearbook, 18, 229-254. 